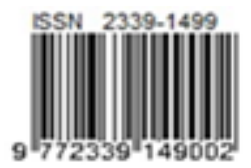

\title{
Pengembangan Alat Bantu Material handling untuk Meminimasi Beban Kerja Operator Produksi Crank Case di PT.X
}

\author{
Yansen Theopilus ${ }^{1}$, William Jonathan' ${ }^{2}$, Yusan Gustin ${ }^{3}$ \\ 1,2,3) Fakultas Teknologi Industri, Jurusan Teknik Industri, Universitas Katolik Parahyangan \\ Jl. Ciumbuleuit 94, Bandung 40141 \\ Email: 1)yansen_theopilus@unpar.ac.id, 2)williamjonathan71@yahoo.com, 3)yusan_14@yahoo.co.id
}

\begin{abstract}
This research aims to evaluate the workload of production operators at PT. $X$ and develop a product/tools that can minimize the workload of production operators in PT.X factory. PT.X is a motorcycle manufacture company that produces sport bike, duck bike, and scooter bike along with its components. One of the main components produced in PT. $X$ is crankcase that function as a house for motorcycle machine components such as generator, oil pumps, clutches, crankshaft, transmission gear, and lubricating oil. This research focuses on crankcase production because the crankcase production operators have the most complaints regarding workload compared to others. The research begins by evaluating the workload of the operators on the initial working system. The evaluation data is collected by some method such as direct field observation, direct measurement, and interview with the operators. After that, the data is processed to evaluate the mental and physical workload of the operators using NIOSH, RULA, and NASA-TLX methods. The Evaluation results show that there are several operators that have an excessive workload, especially for the material handling work. This activity results Lifting Index value of more than 1, a RULA value of more than 5, and a NASA-TLX value greater than 80 . Based on the evaluation, this research developed a material handling tool in the form of workpiece basket lifting equipment using a combination of pneumatic and hydraulic principles that can minimize the workload of the crankcase production operator at PT. X. This tool can eliminate a bending movement which is the source of problem in the operator's workload. The result of the evaluation of this tool application shows that the use of the tool can produce a reasonable workload for all crankcase production operators at PT. $X$.
\end{abstract}

Keywords: Workload, Material Handling, Product Development, Tool, Production

\section{Abstrak}

Penelitian ini bertujuan untuk melakukan evaluasi beban kerja operator produksi di PT.X dan mengembangkan sebuah alat yang dapat meminimasi beban kerja operator produksi di salah satu pabrik PT.X. PT.X memproduksi sepeda motor berjenis sport, bebek, dan skuter beserta komponen utamanya. Salah satu komponen utama yang diproduksi adalah crankcase yang berfungsi sebagai rumah bagi komponen generator, pompa oli, kopling, crankshaft, gigi transmisi, dan oli pelumas pada sepeda motor. Penelitian ini berfokus pada produksi crankcase karena operator produksi pada bagian ini memiliki paling banyak keluhan mengenai beban kerja dibandingkan dengan bagian lainnya. Penelitian diawali dengan mengevaluasi beban kerja terhadap sistem kerja kondisi awal dengan cara observasi langsung, pengukuran stasiun kerja langsung, serta wawancara langsung kepada para operator produksi crankcase. Setelah itu, data diolah untuk mengevaluasi beban kerja fisik dan mental operator menggunakan metode NIOSH, RULA, dan NASA-TLX. Hasil evaluasi menunjukkan bahwa terdapat beberapa operator yang memiliki beban kerja yang berlebihan, khususnya dalam pekerjaan pemindahan benda kerja dari keranjang pembawa benda kerja ke mesin kerja dan sebaliknya. Aktivitas tersebut menghasilkan rata-rata Lifting Index lebih dari 1, nilai RULA lebih dari 5, dan nilai NASA-TLX lebih besar dari 80 . Berdasarkan hasil evaluasi tersebut, penelitian ini mengembangkan rancangan alat bantu material handling berupa alat pengangkat keranjang pembawa benda kerja menggunakan kombinasi prinsip pneumatik dan hidrolik yang dapat meminimasi beban kerja operator produksi crankcase di PT.X. Alat ini dapat menghilangkan gerakan membungkuk operator yang menjadi sumber masalah. Hasil evaluasi terhadap aplikasi dari rancangan alat ini menunjukkan bahwa penggunaan alat dapat menghasilkan beban kerja yang wajar bagi seluruh operator produksi crankcase di PT.X

Kata kunci: Pengembangan Produk, Alat Bantu, Beban Kerja, Material handling, Produksi 


\section{Pendahuluan}

Seiring dengan perkembangan ilmu pengetahuan, teknologi, dan masuknya era globalisasi, sektor bisnis di Indonesia mengalami perkembangan yang sangat pesat. Perkembangan pesat ini sangat berdampak pada persaingan di industri sepeda motor yang sangat ketat karena banyaknya produsen sepeda motor di Indonesia. Sejak tahun 2014 hingga triwulan 1 tahun 2017, permintaan sepeda motor tiap tahunnya dapat mencapai lebih dari 3 juta unit (Bappenas, 2017).

Melihat fenomena ini, PT.X sebagai produsen sepeda motor dengan jumlah produksi terbesar di Indonesia ingin selalu meningkatkan kapasitas produksinya. Salah satu upaya yang dilakukan adalah dengan mendorong pekerjanya untuk memproduksi sepeda motor beserta komponennya secepat dan sebanyak mungkin.

Upaya tersebut seringkali berjalan baik bagi perusahaan, namun tidak selalu berjalan dengan baik bagi pekerja yang berhubungan langsung dengan kegiatan produksi, khususnya operator produksi. Beberapa perusahaan tidak memperhatikan bagaimana kenyamanan atau beban kerja pekerjanya, baik itu dari aspek ergonomi di tempat kerja, lingkungan fisik dan mental, material handling, kesehatan dan keselamatan kerja, dan aspekaspek lainnya.

Secara langsung maupun tidak langsung, kondisi pekerja dan bagaimana ia bekerja akan mempengaruhi produktivitas perusahaan. Sistem kerja yang nyaman dan aman akan berdampak pada produktivitas pekerja yang optimal. Hal tersebut berdampak pula pada keuntungan bagi perusahaan. Selain itu, sistem kerja yang nyaman dan aman juga akan berdampak pada kesehatan dan keselamatan pekerja. Pekerja yang tidak sehat akan menimbulkan kerugian bagi perusahaan berupa biaya pengobatan pekerja yang menjadi tanggungan perusahaan dan juga biaya yang ditimbulkan karena produktivitas pekerja yang tidak optimal. Oleh karena itu, kesehatan dan keselamatan pekerja harus menjadi prioritas utama manajemen perusahaan karena dapat membuat para pekerja hidup aman, meningkatkan produktivitas pekerja, dan mengurangi biaya perusahaan (Jonathan, 2016).

Oleh karena itu, penelitian ini mencoba mengevaluasi beban kerja operator produksi di
PT.X dan mengembangkan suatu alat bantu untuk meminimasi beban kerja operator produksi di PT.X. Penelitian berfokus pada operator produksi komponen crankcase motor karena operator produksi pada bagian ini yang memiliki banyak keluhan mengenai kenyamanan bekerja.

\section{Metode Penelitian}

\section{Antropometri}

Antropometri adalah pengukuran dimensi anggota tubuh manusia (Phinyomark, 2014), yang kemudian data ini akan digunakan untuk pertimbangan perancangan alat-alat yang digunakan oleh manusia. Menurut Stevenson (1996), antropometri dibagi menjadi 2 bagian, yaitu antropometri statis dan antropometri dinamis. Antropometri statis adalah pengukuran dimensi tubuh manusia pada saat tubuh dalam posisi diam (tidak bergerak) dan linear pada permukaan tubuh. Antropometri dinamis adalah pengukuran dimensi tubuh manusia pada saat tubuh dalam posisi bergerak melakukan kegiatannya. Contohnya adalah putaran pergerakan pinggul, putaran pergelangan tangan dan lainnya.

Dalam pengukuran dimensi tubuh manusia, dimensi tubuh manusia dapat dipengaruhi oleh beberapa faktor seperti umur, jenis kelamin, dan suku bangsa (Sutalaksana, 2006). Pada umumnya, manusia akan tumbuh hingga umur 20 tahun untuk pria dan 17 tahun untuk wanita Setelah melewati umur ini, ukuran tubuh manusia akan tetap. Jenis kelamin yang berbeda tentu akan mempengaruhi dimensi tubuh seseorang. Misalnya, pria memiliki dimensi tubuh yang kecil pada dada dan pinggul. Suku bangsa juga mempengaruhi dimensi tubuh seseorang. Misalnya, orang Asia mempunyai dimensi tubuh yang relatif lebih kecil dibanding dengan orang Eropa.

\section{Biomekanika}

Biomekanika merupakan ilmu yang mempelajari pergerakan sesuatu dengan menggunakan kombinasi ilmu mekanika, ilmu biologi dan fisiologi (Knudson, 2007). Dalam prakteknya, biomekanika mempelajari kekuatan dan ketelitian manusia dalam melakukan pekerjaannya. Selain itu, biomekanika juga mempelajari hubungan pekerja dengan alat-alat kerja dan lingkungan kerja. Terdapat 3 faktor yang mempengaruhi biomekanika yaitu faktor diri (contoh: umur dan 
jenis kelamin), sikap kerja, dan jenis kerja. Biomekanika sangat berhubungan dengan pekerjaan yang bersifat material handling seperti pengangkatan dan pemindahan benda secara manual menggunakan otot tubuh. Penanganan material secara manual merupakan aktivitas yang selalu ada dalam industri manufaktur dan industri pengolahan (Umami et al., 2014). Aktivitas manual handling yang tidak tepat dapat menimbulkan kecelakaan kerja terutama pada bagian tulang punggung belakang tubuh. Pengangkatan yang dilakukan secara manual oleh operator memiliki resiko membuat tulang punggung mengalami tekanan berlebih sehingga hal ini akan berdampak buruk bagi operator.

\section{NIOSH Recommended Weight Limit (RWL)}

The National Institute for Occupational and Health (NIOSH) merupakan suatu lembaga yang menangani masalah kesehatan dan keselamatan kerja. $\mathrm{NIOSH}$ mangatasi masalah dengan menganalisis kekuatan manusia dalam memindahkan dan mengangkat benda serta merekomendasikan batas maksimum benda yang dapat diangkut oleh pekerja melalui nilai Recommended Weight Limit (RWL). RWL merupakan batas dari beban yang dapat diangkat oleh seorang pekerja tanpa menimbulkan resiko cedera meskipun pekerjaan tersebut dilakukan secara berulang dan dalam jangka waktu yang lama. Menurut Waters (1994), perhitungan RWL dapat dihasilkan dengan menggunakan Pers. 1.

\section{$\mathrm{RWL}=\mathrm{LC} \times \mathrm{HM} \times \mathrm{VM} \times \mathrm{DM} \times \mathrm{AM} \times \mathrm{FM} \times \mathrm{CM} \quad$ Pers. 1}

$\begin{array}{ll}\text { RWL } & \text { : Batas beban yang rekomendasi } \\ \text { LC } & \text { : Konstanta pembebanan }=23 \mathrm{~kg} \\ \mathrm{HM} & : \text { Faktor pengali horizontal }=25 / \mathrm{H} \\ \mathrm{DM} & : \text { Faktor pengali perpindahan } \\ & 0.82+4.5 / \mathrm{D} \\ \mathrm{AM} & : \text { Faktor pengali asimetrik } \\ & 1-(0.0032 \mathrm{~A}) \\ \mathrm{CM} & : \text { Faktor pengali kopling } \\ \mathrm{FM} & : \text { Faktor pengali frekuensi } \\ \mathrm{VM} & : \text { Faktor pengali vertikal } \\ & 1-(0.003[\mathrm{~V}-75])\end{array}$

Lifting Index (LI) merupakan perbandingan nilai antara berat beban benda dengan berat yang direkomendasikan. Nilai LI menunjukkan nilai estimasi relatif atas tekanan fisik yang berhubungan dengan pengangkatan secara manual. Lifting Index dapat dihitung dengan menggunakan Pers.2.

Lifting index $=\frac{\text { Load weight }}{\text { Recommended Weight Limit }} \quad$ Pers. 2

Menurut Waters (1994), Jika nilai $\mathrm{LI}<1$, berat benda yang diangkat oleh pekerja tidak melebihi berat yang direkomendasikan untuk diangkat. Sebaliknya, jika nilai LI>1, maka berat benda yang diangkat oleh pekerja melebihi berat yang direkomendasikan untuk diangkat dan dapat mengakibatkan resiko cedera pada tulang belakang.

\section{NASA-TLX}

NASA-TLX adalah skala multidimensi yang dirancang untuk mendapatkan estimasi beban kerja dari satu atau banyak operator saat mereka melakukan tugas atau setelahnya (Hart, 2006). NASA-TLX menghasilkan skor beban kerja secara keseluruhan berdasarkan penilaian 6 sub skala yang berkaitan dengan beban kerja pekerja. Subskala tersebut adalah kebutuhan mental, kebutuhan fisik, kebutuhan waktu, performansi, usaha, dan tingkat frustasi.

Proses perhitungan menggunakan NASATLX dilakukan dalam 2 fase yaitu fase pembandingan skala dan penilaian. Skala yang digunakan dapat dilihat pada Gambar 1 .

\section{Rapid Upper Limb Assessment}

Rapid Upper Limb Assessment (RULA) adalah alat evaluasi yang digunakan untuk menganalisis resiko ergonomis pekerja terkait kelainan postur, gaya dan penggunaan otot pada saat bekerja (Middlesworth, 2007). Hasil analisis dari RULA akan menunujukkan derajat kecenderungan pekerja dalam mengalami suatu resiko dan menyediakan metode untuk membantu dalam penyelidikan lebih lanjut. Nilai rendah yang dihasilkan RULA tidak memberikan jaminan bahwa tempat kerja terbebas dari bahaya ergonomi begitu pula sebaliknya nilai RULA yang tinggi belum tentu menggambarkan bahwa tempat kerja memiliki banyak masalah. Lembar penilaian pekerja RULA dapat dilihat pada Gambar 2.

Kategori nilai RULA dapat dilihat pada Tabel 1. 


\begin{tabular}{|c|c|}
\hline \multicolumn{2}{|c|}{ Rating Scale Definitions } \\
\hline $\begin{array}{c}\text { Title } \\
\text { MENTAL DEMAND }\end{array}$ & $\begin{array}{l}\text { Descriptions } \\
\text { How much mental and perceptual activily } \\
\text { was required (e.g-, thinking, deciding. } \\
\text { calculating, remembering, looking, } \\
\text { scarching, etc. P Was the task easy or } \\
\text { demanding, simple or complex, exacting or } \\
\text { forgiving? }\end{array}$ \\
\hline PHYSICAL DEMAND & $\begin{array}{l}\text { How much physical activity was requited } \\
\text { (e.g., pushing, pulling, furning controlling. } \\
\text { activating, etc. pl Was the task casy or } \\
\text { demanding, slow or brisk, slack or } \\
\text { strenuous, restful or laborious? }\end{array}$ \\
\hline TEMPORAL DEMAND & $\begin{array}{l}\text { How much time pressure did you feel due to } \\
\text { the rate or pace at which the tasks or task } \\
\text { elements occurred? Was the pace slow and } \\
\text { leisurely or rapid and frantic? }\end{array}$ \\
\hline PERFORMANCE & $\begin{array}{l}\text { How successful do you think you were in } \\
\text { accomplishing the goals of the task set by } \\
\text { the experimenter (or yourself)? How } \\
\text { sabisfied were you with your performance in } \\
\text { accomplishing these goals? }\end{array}$ \\
\hline EFFORT & $\begin{array}{l}\text { How hard did you have to work (mentally } \\
\text { and physically) to accomplish your level of } \\
\text { performance? }\end{array}$ \\
\hline FRUSTRATION LEVEL. & $\begin{array}{l}\text { How insecure, discouraged, irritated, } \\
\text { stressed and annoyed versus secure. } \\
\text { gratified, content, relaxed and complacent } \\
\text { did you feel during the task? }\end{array}$ \\
\hline
\end{tabular}

Gambar 1. Skala NASA-TLX

(Sumber: Trujillo, 2011)

\section{Pengembangan Produk}

Menurut Ulrich dan Eppinger (2012), pengembangan produk merupakan kumpulan aktivitas yang dimulai dengan adanya kebutuhan produk untuk dikembangkan dan diakhiri dengan proses produksi produk. Tahapan yang umum dilakukan dalam proses pengembangan produk dapat dilihat pada Gambar 3.

Tahapan pengembangan produk menurut Ulrich dan Eppinger (2012) dimulai dengan tahap merencanakan proyek melalui pernyataan misi yang meliputi deskripsi proyek,

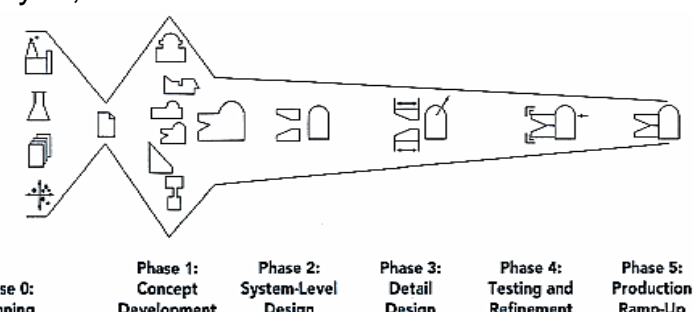

Gambar 3. Tahap Pengembangan Produk

(Sumber: Ulrich dan Eppinger, 2012)

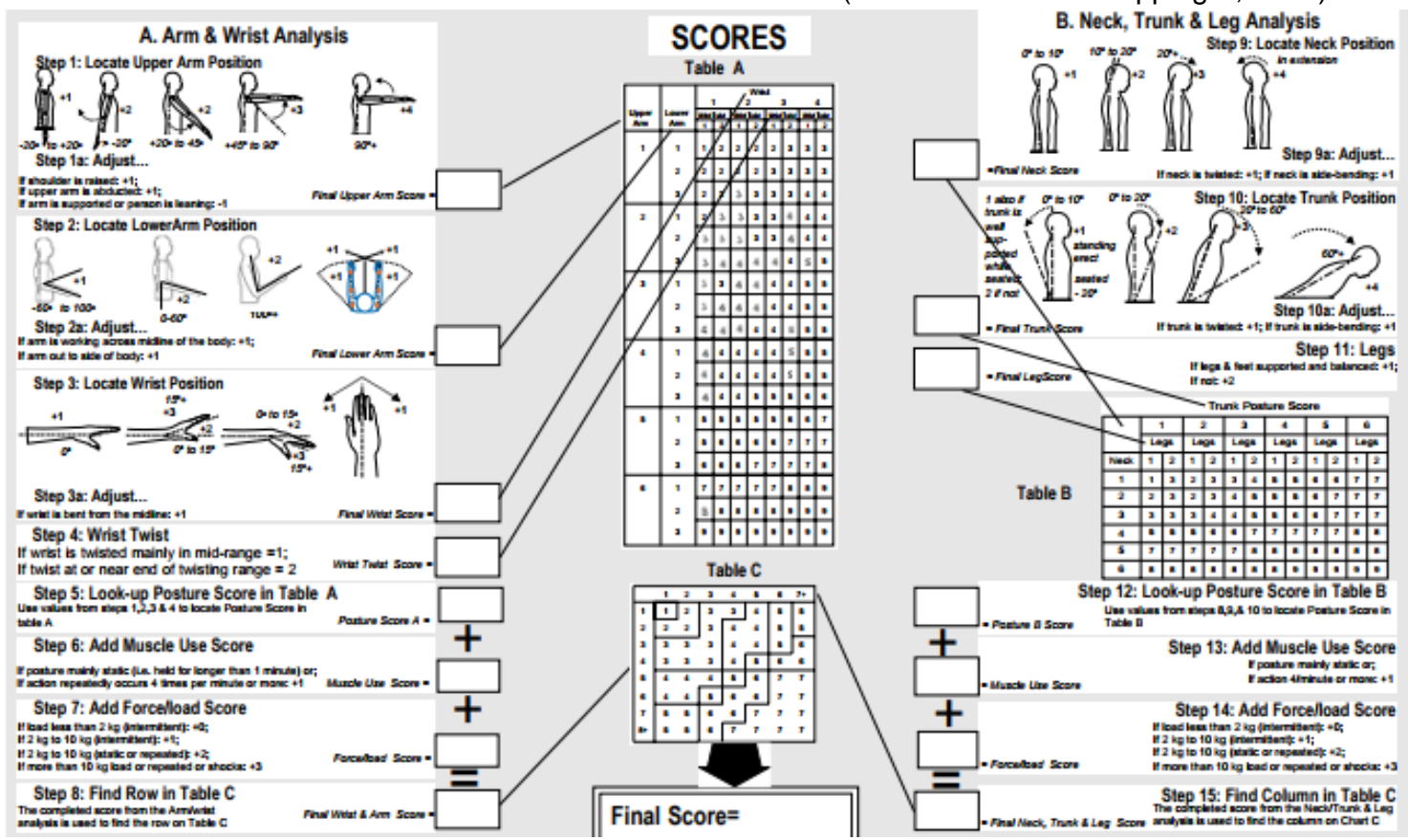

Gambar 2. RULA Employee Assessment Worksheet

(Sumber: McAtamney dan Corlett, 1993)

Tabel 1. Kategori RULA (Ansari dan Sheikh, 2014)

\begin{tabular}{|l|c|c|l|l|}
\hline $\begin{array}{l}\text { Nilai } \\
\text { RULA }\end{array}$ & $1-2$ & $3-4$ & $5-6$ & 7 \\
\hline Resiko & - & Rendah & Sedang & Tinggi \\
\hline Aksi & - & Selidiki & $\begin{array}{l}\text { Selidiki } \\
\text { dan } \\
\text { perbaiki }\end{array}$ & $\begin{array}{l}\text { harus } \\
\text { segera } \\
\text { perbaiki }\end{array}$ \\
\hline
\end{tabular}

keuntungan yang ditawarkan, tujuan pengembangan, target konsumen yang dituju, dan pemangku kepentingan dalam proyek. Jika perencanaan sudah jelas, dilakukan identifikasi kebutuhan target konsumen agar produk yang dihasilkan sesuai dengan kebutuhan konsumen. Setelah itu, tahap selanjutnya adalah pengembangan konsep 
produk berdasarkan rencana dan kebutuhan konsumen. Jika dihasilkan beberapa konsep produk, maka konsep-konsep tersebut perlu melalui tahap concept screening dan scoring berdasarkan kriteria tertentu untuk mendapatkan satu konsep produk yang paling baik untuk dikembangkan lebih lanjut.

Setelah itu, dilakukan perancangan sistem dari produk dan juga perancangan detail dari produk. Setelah produk selesai dirancang, dilakukan pengujian terhadap produk dan dilakukan perbaikan bila dibutuhkan. Setelah produk selesai dirancang dan lolos uji, tahap terakhir adalah memproduksi produk agar siap dipasarkan.

Objek penelitian ini adalah operator produksi pada stasiun kerja crankcase machining pada pabrik sepeda motor PT.X. Metodologi penelitian yang dilakukan dapat dilihat pada Gambar 4.

\begin{tabular}{|c|}
\hline Penentuan Objek Penelitian \\
\hline$\downarrow$ \\
\hline Observasi Pendahuluan \\
\hline$\downarrow$ \\
\hline Identifikasi dan Penentuan Masalah \\
\hline$\downarrow$ \\
\hline Pengumpulan Data \\
\hline $\begin{array}{l}\text { - Sistem Produksi Crankcase } \\
\text { - Pembagian Kerja Operator } \\
\text { - Keranjang Pembawa Benda Kerja } \\
\text { - Layout dan Ukuran Tempat Kerja } \\
\text { - Data Antropometri }\end{array}$ \\
\hline$\downarrow$ \\
\hline Pengolahan Data \\
\hline $\begin{array}{l}\text { - Evaluasi Sistem Kerja } \\
\text { - Perhitungan Beban Kerja Operator }\end{array}$ \\
\hline$\stackrel{\downarrow}{\text { Pengembangan Alat Bantu Material Handling }}$ \\
\hline $\begin{array}{l}\text { - Penentuan Mission Statement } \\
\text { - Benchmarking Produk Serupa } \\
\text { - Perancangan Produk Alat Bantu MH }\end{array}$ \\
\hline$\downarrow$ \\
\hline Kesimpulan dan Rekomendasi \\
\hline
\end{tabular}

Gambar 4. Metodologi Penelitian

\section{Hasil dan Pembahasan}

\section{Proses Produksi Crankcase}

Crankcase merupakan bagian cover engine sepeda motor dimana di dalamnya merupakan tempat pemasangan crank shaft, main shaft, cylinder head, serta cylinder comp, tempat penampungan oli, tempat piston beserta mekanismenya, dan tempat sistem gear pada mesin. Crankcase terbuat dari balok alumunium HD2 yang dicairkan dengan temperatur pemanasan sangat tinggi, lalu dicetak menggunakan High Pressure Die Casting sehingga membentuk sebuah blank case (case yang sudah berbentuk namun belum memiliki lubang dan memiliki profil kasar).

Stasiun crankcase machining bertujuan untuk menghaluskan permukaan dan memberi lubang-lubang yang kompleks pada blank crankcase sehingga menjadi produk akhir crankcase. Crankcase terdiri dari crankcase bagian kiri, crankcase bagian kanan, dan mission case (mission case hanya digunakan untuk sepeda motor tipe skuter), dimana ketiganya mengalami proses machining yang berbeda. Layout stasiun kerja produksi crankcase dapat dilihat pada Gambar 5 dan 6 .

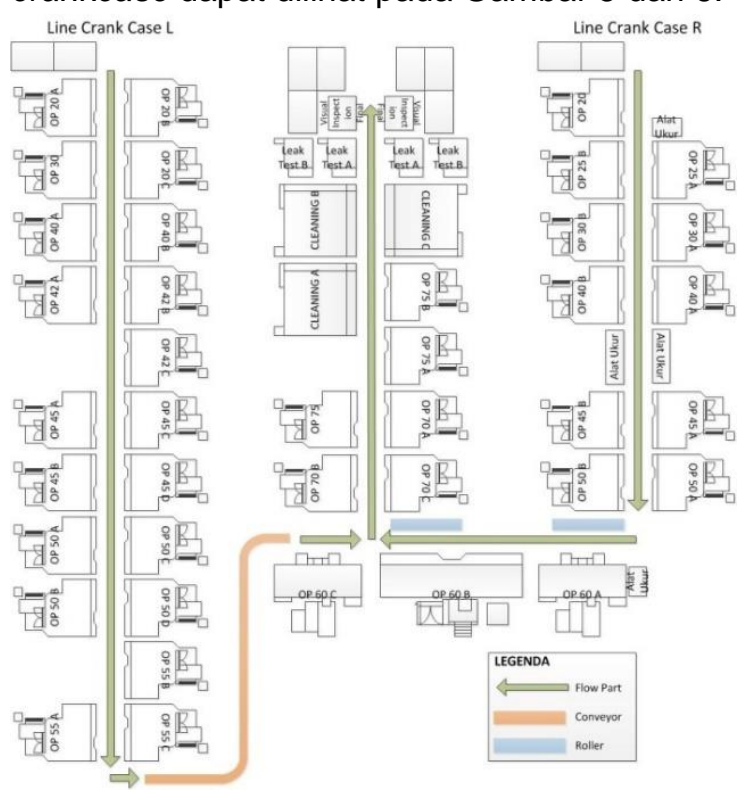

Gambar 5. Layout Stasiun Kerja Machining Komponen Crankcase L/R

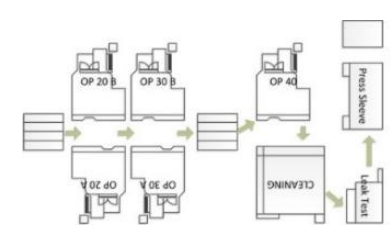

Gambar 6. Layout Stasiun Kerja Machining Komponen Mission Case

Proses produksi semua komponen crankcase diawali dengan proses casting untuk membentuk kerangka dari crankcase. Setelah bentuk luar masing-masing komponen crankcase terbentuk, dilanjutkan dengan proses machining. Proses machining komponen crankcase $\mathrm{R}$ dan $\mathrm{L}$ sama, namun urutan proses machining komponen mission case berbeda. 
Urutan Proses machining komponen crankcase $R$ dan $L$ adalah sebagai berikut:

1. OP 10 Rotary Milling: penghalusan permukaan luar hasil casting.

2. OP 20 Tapping Center: pembuatan ulir pada lubang untuk pin basic dengan diameter $8 \mathrm{~mm}$.

3. OP 25 Tapping Center: drilling diameter $6,5 \mathrm{~mm}$ untuk lubang joint dan drilling diameter $8 \mathrm{~mm}$ untuk saluran oli.

4. OP 30 Tapping Center: drilling diameter 5,5 $\mathrm{mm}$ dan tapping $\mathrm{M} 6$ yang berfungsi untuk mengikat engine.

5. OP 40 Tapping Center: Drilling dengan berbagai posisi dan diameter untuk mengikat pompa oli.

6. OP 45 Tapping Center: rough boring untuk engine hanger, drilling dan tapping M10 untuk mengikat knalpot, dan drill spot face untuk level oli.

7. OP 50 Tapping Center: end milling untuk dudukan pompa oli, boring untuk membuat rumah crankshaft, drilling untuk membuat standar tengah dan lubang oli, dan rough boring untuk membuat dudukan crankshaft.

8. OP 60 Fine Boring: penghalusan pada permukaan lubang yang masih kasar.

9. OP 70 Comp Face Milling: face milling untuk membuat lubang dan pengikat walkthrough.

10. OP 75 Tapping Center: drilling untuk lubang oli dan drill spot face untuk lubang penguras oli.

11. OP 80 Cleaning: menembakkan air dan angin untuk membersihkan permukaan benda kerja dari kotoran seperti scrap, debu, dan lain-lain.

12. OP 100 Leak Tester: menembakkan angin dan air ke benda kerja untuk menguji kebocoran benda kerja.

13. Final Inspection: pengecekan semua hasil machining pada crankcase.

Urutan Proses machining komponen crankcase $L$ dan $R$ hanya berbeda pada posisi operasi saja. Urutan proses machining komponen mission case adalah sebagai berikut:

1. OP 10 Rotary Milling: penghalusan permukaan luar hasil casting.

2. OP 20 Tapping Center: end milling dan drilling untuk tempat dudukan kampas rem, drilling untuk membuat rumah press sleeve, end milling untuk membuat joint $\mathrm{L}$, dan reamer untuk membuat pin basic dan rumah pipa udara.

3. OP 30 Tapping Center: Reamer, drilling, rough boring, spot face, dan boring finish.

4. OP 40 Turning: proses insert untuk alur pembuangan udara dan membersihkan kotoran.

5. OP 50 Cleaning: pembersihan pada mission case agar bebas dari scrap.

6. OP 60 Leak tester: uji kebocoran pada mission case.

7. OP 70 Press Sleeve and oil seal: pemasangan sleeve dan rubber seal yang berfungsi sebagai dudukan tuas rem.

Waktu siklus produksi untuk komponen crankcase $\mathrm{R}$ dan $\mathrm{L}$ adalah 27 detik, sedangkan untuk mission case 30 detik. Komponen crankcase $\mathrm{R}$ memiliki bobot seberat $2,5 \mathrm{~kg}$, crankcase $\mathrm{L}$ seberat $3 \mathrm{~kg}$, dan mission case seberat $1 \mathrm{~kg}$. Crankcase hasil produksi dapat dilihat pada Gambar 7.

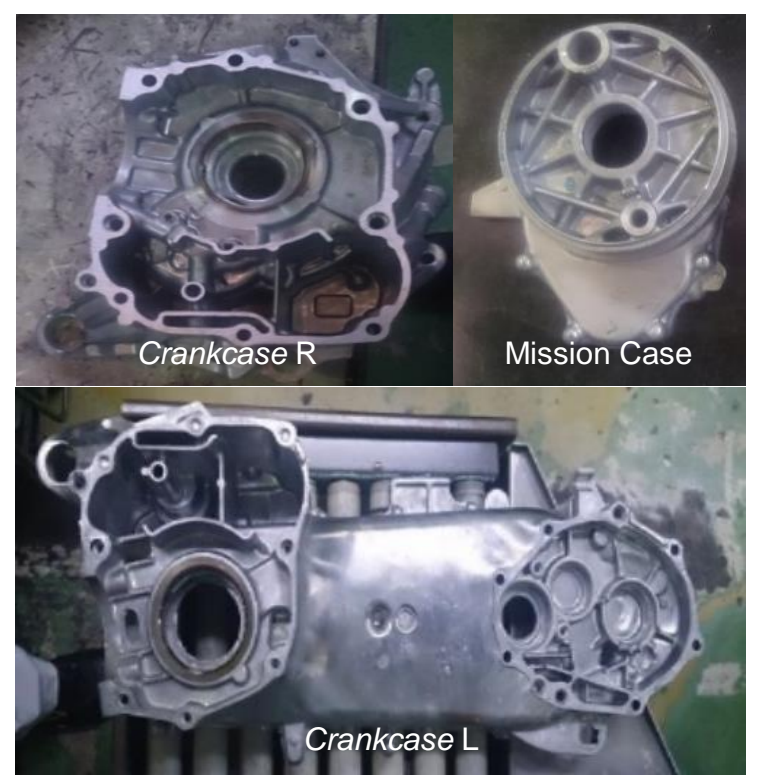

Gambar 7. Crankcase

Untuk memindahkan material antar stasiun kerja atau antar mesin dalam stasiun kerja, digunakan keranjang dorong sebagai alat material handling. Keranjang memiliki 4 roda kecil dan harus didorong secara manual oleh operator produksi. Satu keranjang dapat menampung 96 unit crankcase R, 50 unit crankcase L, atau 200 unit mission case. Pada umumnya, satu keranjang hanya 
membawa 1 jenis komponen. Keranjang hanya memiliki 1 sisi terbuka di bagian atas, sehingga untuk mengambil benda kerja pada bagian bawah keranjang, operator produksi harus melakukan gerakan membungkuk yang cukup dalam. Pada stasiun kerja, terdapat 2 jenis keranjang dengan ukuran yang identik. Gambar keranjang pembawa benda kerja dapat dilihat pada Gambar 8. Pada bagian depan keranjang terdapat engsel yang dapat dibuka tutup seperti dapat dilihat pada gambar.

Dalam satu shift kerja, rata-rata produksi crankcase $\mathrm{R}$ dan $\mathrm{L}$ adalah sebanyak 737 unit, sedangkan rata-rata produksi mission case sebanyak 740 unit. Dengan pertimbangan bahwa setengah dari jumlah produksi tersebut diambil atau diletakkan di keranjang oleh operator dalam posisi membungkuk dan operator mengambil atau meletakkan dua buah benda kerja dalam sekali membungkuk, maka operator OP10 crank case $\mathrm{R}$, crank case $\mathrm{L}$, dan mission case melakukan lebih dari 370 kali gerakan membungkuk dalam 1 shift. Selain itu, operator OP20 crank case R dan L, operator OP20 mission case, operator OP 70 mission case, dan operator Inspeksi crankcase $\mathrm{R}$ dan $\mathrm{L}$ melakukan lebih dari 369 kali gerakan membungkuk dalam 1 shift.

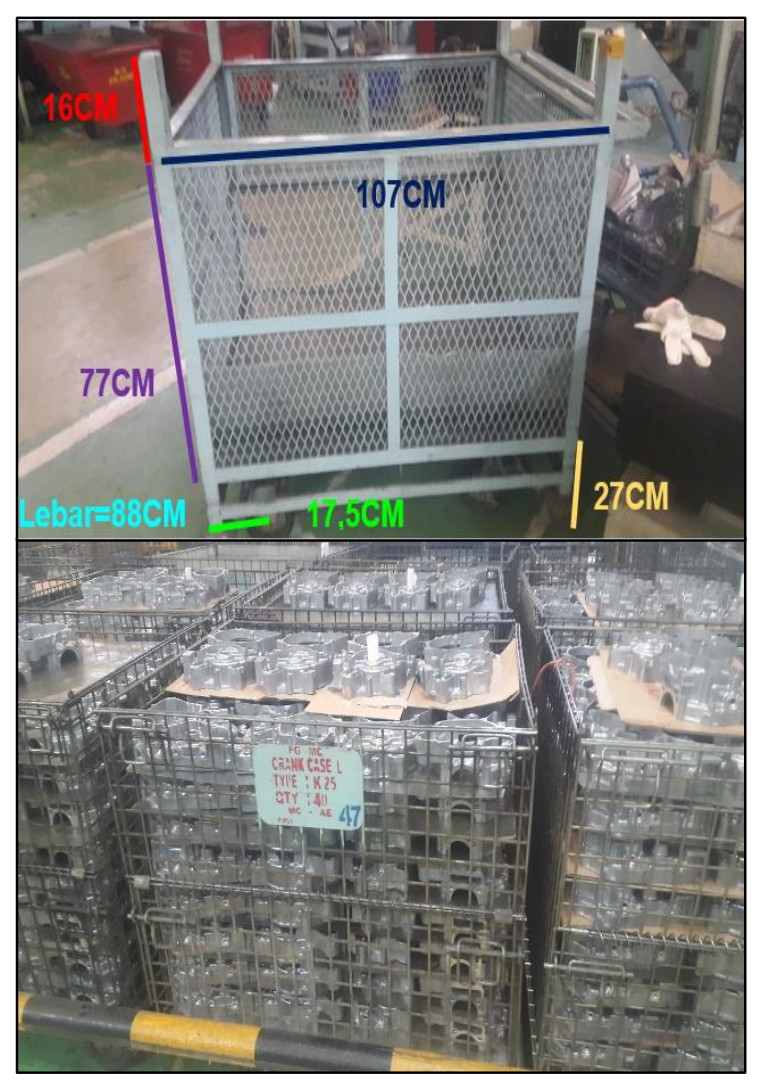

Gambar 8. Keranjang Pembawa Benda Kerja

\section{Evaluasi Beban Kerja}

Beban kerja operator merupakan perbandingan dari kapasitas kemampuan yang dimiliki seorang pekerja dengan kapasitas kemampuan yang dituntut oleh pekerjaan yang ia lakukan. Bila kapasitas yang dituntut oleh pekerjaannya lebih besar, maka dapat dikatakan bahwa beban kerja pekerja tersebut tergolong tinggi. Berdasarkan ilmu ergonomi, beban kerja yang dapat dialami oleh pekerja terdiri dari beberapa jenis, diantaranya beban pengangkatan apabila pekerja melakukan pengangkatan dalam pekerjaannya, beban kerja fisik, dan juga beban kerja mental.

Hasil penelitian pendahuluan menunjukkan bahwa potensi beban kerja yang terbesar adalah pada aktivitas material handling benda kerja dari dan ke dalam keranjang pembawa benda kerja. Oleh karena itu, penelitian ini mengevaluasi beban kerja pengangkatan dan pemindahan serta beban kerja mental dari operator produksi crankcase PT.X. Beban kerja mental juga dapat dipangaruhi oleh aktivitas fisik yang berlebih (DiDomenico dan Nussbaum, 2011). Oleh karena itu, beban kerja mental juga perlu dievaluasi dalam penelitian ini. Metode NIOSH dan metode RULA dipilih karena merupakan metode yang umum digunakan untuk mengukur beban kerja pengangkatan dan pemindahan benda kerja. Metode NASA-TLX dipilih karena merupakan metode yang sangat baik untuk mengukur beban kerja mental.

Operator OP10, OP20, dan QC merupakan operator yang memasukkan benda kerja ke keranjang atau mengeluarkan benda kerja dari keranjang. Maka dari itu, dilakukan perhitungan beban kerja untuk operatoroperator tersebut. Perhitungan beban kerja dengan metode $\mathrm{NIOSH}$ dilakukan terhadap postur tubuh pekerja saat mengambil atau meletakkan benda kerja pada keranjang benda kerja bagian atas dan bagian bawah. Benda kerja pada keranjang bagian atas adalah benda kerja yang diletakkan pada tumpukan pertama dari permukaan atas keranjang bila terisi penuh. Benda kerja pada keranjang bagian bawah adalah benda kerja yang diletakkan pada tumpukan pertama dari dasar keranjang bila terisi penuh. Hasil perhitungan RWL dan $\mathrm{LI}$ dengan metode $\mathrm{NIOSH}$ dari beban pengangkatan dan pemindahan benda kerja dapat dilihat pada Tabel 2. 
Berdasarkan hasil perhitungan, dapat dilihat bahwa seluruh beban kerja pengangkatan benda kerja dari dan ke keranjang benda kerja bagian bawah memiliki nilai lebih besar dari 1. Beberapa beban kerja pengangkatan benda kerja dari dan ke keranjang benda kerja bagian atas juga memiliki nilai lebih besar dari 1 . Hasil ini menunjukkan bahwa beban pengangkatan dan pemindahan operator-operator tersebut sudah melewati batas yang ideal untuk kesehatan dan keselamatan pekerjaan dari operator. Beban lebih besar dirasakan saat operator mengambil atau menaruh benda kerja di keranjang bagian bawah.

Evaluasi beban kerja operator menggunakan metode RULA dilakukan terhadap 3 posisi tubuh, yaitu saat mengangkat benda kerja dari keranjang bagian bawah, posisi tubuh saat mengangkat benda kerja dari keranjang bagian atas, dan juga posisi tubuh saat mengangkat benda kerja dari meja mesin. Berdasarkan hasil perhitungan dengan mengacu pada tabel RULA assessment worksheet, didapatkan nilai RULA untuk posisi tubuh mengangkat benda kerja dari keranjang bagian bawah adalah sebesar 7.

Nilai RULA untuk posisi tubuh mengangkat benda kerja dari keranjang bagian atas adalah 5. Nilai RULA untuk posisi tubuh saat mengangkat benda kerja dari meja mesin sebesar 4. Dengan hasil ini, dapat disimpulkan bahwa posisi tubuh dengan beban pengangkatan yang sangat mendesak untuk diperbaiki adalah posisi tubuh mengangkat benda kerja dari keranjang bagian bawah.

Evaluasi beban mental operator-operator yang berinteraksi dengan keranjang benda kerja dilakukan dengan menghitung 6 subskala yang mempengaruhi mental pekerja. Hasil perhitungan menunjukkan bahwa rata-rata beban mental operator OP10 sebesar 83,3, OP20 sebesar 82, dan OP QC sebesar 86. Karena batas beban mental yang disarankan adalah sebesar 80 (Hart dan Staveland, 1988), maka beban mental dari operator ketiga operasi tersebut tergolong melampaui batas maksimum (terlalu berat).

\section{Pengembangan Alat Material handling}

Berdasarkan permasalahan yang telah dievaluasi, dilakukan pengembangan produk alat bantu material handling untuk mengurangi- beban kerja operator produksi crankcase yang berhubungan dengan keranjang benda kerja

. Tabel 2. Perhitungan NIOSH

\begin{tabular}{|c|c|c|c|c|}
\hline Operator & Dari & $\mathrm{Ke}$ & $\overline{\mathrm{RWL}}$ & $\mathrm{LI}$ \\
\hline \multirow{8}{*}{ OP 10} & $\begin{array}{l}\text { basket } \mathrm{L} \\
\text { bag bawah }\end{array}$ & mesin op 10 & 2,728 & 1,100 \\
\hline & $\begin{array}{l}\text { basket } \mathrm{L} \\
\text { bag atas }\end{array}$ & mesin op 10 & 2,892 & 1,037 \\
\hline & $\begin{array}{l}\text { basket } \mathrm{R} \\
\text { bag bawah }\end{array}$ & mesin op 10 & 2,471 & 1,012 \\
\hline & $\begin{array}{l}\text { basket } \mathrm{R} \\
\text { bag atas }\end{array}$ & mesin op 10 & 2,210 & 1,131 \\
\hline & mesin op 10 & $\begin{array}{l}\text { basket } \mathrm{L} \\
\text { bag bawah }\end{array}$ & 2,638 & 1,137 \\
\hline & mesin op 10 & $\begin{array}{l}\text { basket } \mathrm{L} \\
\text { bag atas }\end{array}$ & 3,127 & 0,959 \\
\hline & mesin op 10 & $\begin{array}{l}\text { basket } \mathrm{R} \\
\text { bag bawah }\end{array}$ & 1,921 & 1,302 \\
\hline & mesin op 10 & $\begin{array}{l}\text { basket } \mathrm{R} \\
\text { bag atas }\end{array}$ & 1,868 & 1,338 \\
\hline \multirow{8}{*}{ OP20 } & $\begin{array}{l}\text { Basket } \\
\text { bag bawah }\end{array}$ & mesin op 20 & 3,112 & 1,607 \\
\hline & $\begin{array}{l}\text { Basket } \\
\text { bag atas }\end{array}$ & mesin op 20 & 4,759 & 1,051 \\
\hline & $\begin{array}{l}\text { Basket } \\
\text { bag bawah }\end{array}$ & mesin op $20 \mathrm{~A}$ & 4,952 & 1,289 \\
\hline & $\begin{array}{l}\text { Basket } \\
\text { bag atas }\end{array}$ & mesin op 20A & 6,364 & 0,943 \\
\hline & $\begin{array}{l}\text { Basket } \\
\text { bag bawah }\end{array}$ & mesin op 20B & 4,653 & 1,289 \\
\hline & \begin{tabular}{|l|} 
Basket \\
bag atas \\
\end{tabular} & mesin op 20B & 6,364 & 0,943 \\
\hline & \begin{tabular}{|l|} 
Basket \\
bag bawah
\end{tabular} & mesin op 20C & 4,653 & 1,289 \\
\hline & \begin{tabular}{|l} 
Basket \\
bag atas
\end{tabular} & mesin op $20 \mathrm{C}$ & 3,790 & 1,583 \\
\hline \multirow{3}{*}{ QC } & QC & $\begin{array}{l}\text { Basket } \\
\text { bag bawah }\end{array}$ & 2,449 & 1,021 \\
\hline & QC & Basket & 3,414 & 0,732 \\
\hline & & bag atas & & \\
\hline
\end{tabular}

Pengembangan alat bantu dilakukan dengan special purpose dimana produk tidak diproduksi secara masal untuk mendapatkan keuntungan, namun untuk membantu PT.X dalam menyelesaikan masalah yang ditemukan. Pernyataan misi dari pengembangan alat bantu yang dirancang dapat dilihat pada Tabel 3.

Setelah merencanakan pengembangan alat bantu pengangkat keranjang, dilakukan benchmarking. Benchmarking berfungsi untuk melakukan perbandingan terhadap produk yang akan dirancang dengan produk yang sudah ada di pasaran dengan kemiripan fungsi, sehingga diharapkan dapat dirancang produk yang lebih unggul dari produk benchmarking yang ada. Produk benchmark yang digunakan adalah beberapa produk lifter mobil dan lifter sepeda motor. Produk tersebut dipilih karena memiliki kemiripan mekanisme dengan produk yang dirancang. Berdasarkan hasil benchmarking yang dilakukan, didapatkan beberapa masukan mengenai 
spesifikasi dan mekanisme alat bantu yang dikembangkan.

Tabel 3. Pernyataan Misi Pengembangan Alat Bantu

\begin{tabular}{|l|l|}
\hline \multirow{2}{*}{$\begin{array}{l}\text { Deskripsi } \\
\text { Singkat }\end{array}$} & $\begin{array}{l}\text { Alat Bantu Pengangkat } \\
\text { dapat mempermudah dalam } \\
\text { mengambil dan meletakkan } \\
\text { benda kerja pada keranjang. }\end{array}$ \\
\hline $\begin{array}{l}\text { Keunggulan } \\
\text { Produk }\end{array}$ & $\begin{array}{l}\text { - Mudah dioperasikan } \\
\text { - Tahan lama } \\
\text { - Ketinggian dapat diatur sesuai } \\
\text { dimensi tubuh operator }\end{array}$ \\
\hline $\begin{array}{l}\text { Tujuan } \\
\text { Kunci }\end{array}$ & $\begin{array}{l}\text { Mempermudah pekerjaan } \\
\text { operator. Menghindarkan operator dari } \\
\text { cedera. }\end{array}$ \\
\hline $\begin{array}{l}\text { Target } \\
\text { Pemakaian }\end{array}$ & $\begin{array}{l}\text { Perbaikan sistem kerja di } \\
\text { Bagian Crank Case Machining } \\
\text { PT X }\end{array}$ \\
\hline $\begin{array}{l}\text { Pemangku } \\
\text { Kepentingan }\end{array}$ & $\begin{array}{l}\text { Operator Produksi Crankcase } \\
\text { - Maintenance dan teknisi } \\
\text { produk } \\
\text { — Management PT.X }\end{array}$ \\
\hline
\end{tabular}

Setelah melakukan benchmarking, dilakukan penentuan ketinggian keranjang yang ideal untuk diambil oleh operator. Untuk menentukan tinggi ideal, digunakan data antropometri dari 54 operator produksi crankcase yang bersangkutan. Data antropometri dapat dilihat pada Tabel 4 . llustrasi dari data antropometri dapat dilihat pada Gambar 9.

Tabel 4. Data Antropometri Operator

\begin{tabular}{|l|l|c|c|c|c|c|c|}
\hline \multicolumn{2}{|c|}{ Dimensi (cm) } & OP10 & OP20 & $\begin{array}{c}\text { OP20 } \\
\text { A\&B }\end{array}$ & OP20C & QC & OP70 \\
\hline a & Tinggi tubuh & 162 & 160 & 159 & 163 & 171 & 161 \\
\hline $\mathrm{b}$ & $\begin{array}{l}\text { Panjang rentang } \\
\text { tangan kedepan }\end{array}$ & 67 & 66 & 66 & 70 & 80 & 65 \\
\hline tanggi rentang \\
c & $\begin{array}{l}\text { Tingan ke depan } \\
\text { tangan } \\
\text { dari tanah }\end{array}$ & 133 & 132 & 130 & 130 & 143 & 131 \\
\hline d & $\begin{array}{l}\text { Panjang rentang } \\
\text { tangan ke samping }\end{array}$ & 157 & 158 & 158 & 162 & 176 & 154 \\
\hline e $\begin{array}{l}\text { Tinggi telapak } \\
\text { tangan posisi diam } \\
\text { ke tanah }\end{array}$ & 61 & 63 & 58 & 60 & 65 & 64 \\
\hline
\end{tabular}

Tinggi maksimum rentang tangan ke depan dari tanah adalah $143 \mathrm{~cm}$. Jika operator tidak boleh membungkuk pada saat mengambil benda kerja yang terletak dibagian paling bawah dari keranjang, maka keranjang harus dapat dinaikkan dengan alat bantu hingga setinggi $143 \mathrm{~cm}$.

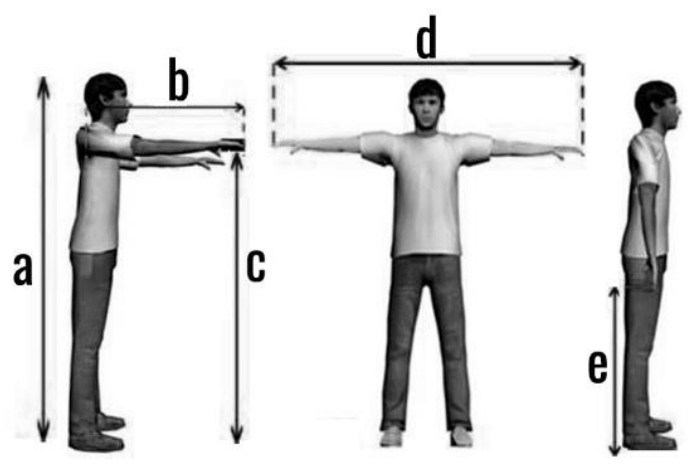

Gambar 9. Ilustrasi Data Antropometri

Posisi ini merupakan posisi maksimum dari tinggi kenaikan keranjang dimana operator tidak perlu membungkuk dalam mengambil benda kerja yang terletak di bagian paling bawah dan paling jauh dari sisi operator mengambil benda kerja. Kenaikan ketinggian tersebut dapat diatur oleh operator melalui sistem kontrol pada alat sesuai dengan dimensi tubuh masing-masing.

Rata-rata rentang tangan ke depan dari tanah adalah sebesar $131,5 \mathrm{~cm}$. Hal ini menunjukkan bahwa tinggi pada saat operator mengambil benda kerja pada bagian paling atas dari keranjang yang baik adalah sebesar $131,5 \mathrm{~cm}$. Agar keranjang berada pada ketinggian tersebut, maka alat bantu pengangkat harus menaikkan ketinggian keranjang dari tanah sebesar $57,5 \mathrm{~cm}$ keatas. Besarnya ketinggian ini didapatkan dengan melakukan pengurangan antara rata-rata tinggi rentang tangan ke depan dari tanah dengan tinggi keranjang tanpa roda. Posisi ini merupakan posisi dari tinggi kenaikan keranjang yang ideal.

Setelah menentukan ketinggian yang ideal, dilakukan pengembangan alternatif dari spesifikasi alat pengangkat dengan menggunakan tabel kombinasi. Tabel kombinasi konsep dapat dilihat pada Tabel 5.

Tabel kombinasi menghasilkan 7 fitur yang yang dapat dikombinasikan dalam merancang alat bantu pengangkat keranjang. Berdasarkan tabel kombinasi, dipilih 1 kombinasi alat bantu pengangkat keranjang yang terbaik. Pemilihan kombinasi-kombinasi akan didasarkan pada kebutuhan dan kenyamanan operator PT $X$. Pada fitur tenaga penggerak, digunakan tenaga penggerak kombinasi pneumatik dan hidrolik. Opsi ini dipilih karena perusahaan memiliki pompa tekanan udara sebesar 3 bar yang dapat difungsikan tanpa penambahan biaya, sehingga prinsip pneumatik bisa digunakan. Namun, tekanan sebesar 6 bar 
tidak cukup kuat untuk mendorong keranjang berisi benda kerja. Oleh karena itu, digunakan mekanisme hidrolik juga agar membuat tekanan sebesar 6 bar mampu mengangkat keranjang berisi benda kerja yang dapat mencapai berat kurang lebih $250 \mathrm{~kg}$. Pada fitur cara pengoperasian, digunakan tekanan udara dalam mendorong mengoperasikan alat bantu pengangkat. Hal ini agar mengurangi pengeluaran energi operator. Apabila digunakan pedal kaki atau tuas, operator lebih cepat lelah karena harus menginjak atau menarik dalam mengoperasikan alat bantu pengangkat.

Tabel 5. Tabel Kombinasi Konsep

\begin{tabular}{|l|l|l|l|}
\hline \multicolumn{1}{|c|}{ Fitur } & \multicolumn{3}{|c|}{ kombinasi } \\
\hline $\begin{array}{l}\text { Tenaga } \\
\text { Penggerak }\end{array}$ & Pneumatik & Mekanik & $\begin{array}{l}\text { Pneumatik- } \\
\text { Hidrolik }\end{array}$ \\
\hline Cara operasi & Tombol & Pedal kaki & Tuas \\
\hline $\begin{array}{l}\text { Sistem } \\
\text { pemasangan } \\
\text { alat }\end{array}$ & $\begin{array}{l}\text { Terdapat } \\
\text { roda di } \\
\text { bagian } \\
\text { bawah }\end{array}$ & $\begin{array}{l}\text { Bongkar } \\
\text { pasang }\end{array}$ & $\begin{array}{l}\text { Tertanam di } \\
\text { tanah }\end{array}$ \\
\hline $\begin{array}{l}\text { Bentuk Kaki } \\
\text { penyangga } \\
\text { Alas }\end{array}$ & Bentuk X & $\begin{array}{l}4 \\
\text { penyangga } \\
\text { di setiap } \\
\text { sisi }\end{array}$ & $\begin{array}{l}1 \\
\text { penyangga } \\
\text { di tengah }\end{array}$ \\
\hline Material alas & $\begin{array}{l}\text { Baja } \\
\text { carbon }\end{array}$ & Besi & Alumunium \\
\hline $\begin{array}{l}\text { Bentuk } \\
\text { Lokator } \\
\text { benda }\end{array}$ & $\begin{array}{l}\text { Capit pada } \\
\text { roda }\end{array}$ & $\begin{array}{l}\text { Diletakkan } \\
\text { secara } \\
\text { langsung }\end{array}$ & $\begin{array}{l}\text { Terdapat } \\
\text { siku-siku } \\
\text { penahan }\end{array}$ \\
\hline $\begin{array}{l}\text { Bentuk alas } \\
\text { pengangkat }\end{array}$ & Lingkaran & $\begin{array}{l}\text { Persegi } \\
\text { panjang }\end{array}$ & $\begin{array}{l}\text { Rangka- } \\
\text { rangka } \\
\text { hollow }\end{array}$ \\
\hline
\end{tabular}

Pada fitur sistem pemasangan alat, alternatif yang digunakan adalah tertanam ditanah. Bentuk kaki penyangga menggunakan 1 penyangga yang berada ditengah. Peletakkan pada posisi tengah dilakukan agar alat bantu dapat menahan keranjang pada pusat massa. Bentuk alas pengangkat, bentuk dari alas pengangkat adalah persegi panjang. Bentuk dari alas pengangkat tidak terlalu mempengaruhi kerja dari alat bantu pengangkat, bentuk ini hanya sebagai tampilan estetika saja.

Material dari alas pengangkat yang digunakan adalah baja karbon. Baja karbon dipilih karena mempunyai kelebihan sebagai berikut: sifat mekanik yang sangat kuat, banyak tersedia di pasaran, dan harganya tidak terlalu mahal. Bentuk penahan keranjang adalah siku-siku yang berguna sebagai lokator 94

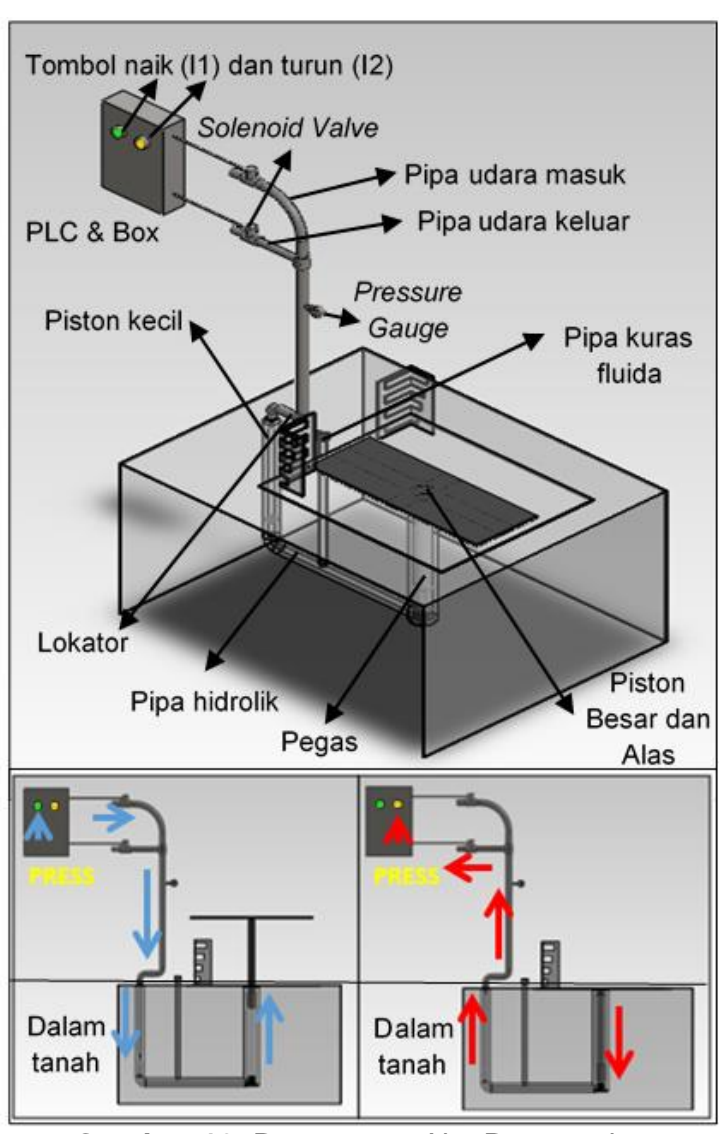

Gambar 10. Rancangan Alat Pengangkat Keranjang

keranjang agar keranjang tidak bergerak pada saat berada pada alat ini.

Berdasarkan hasil perencanaan konsep produk, dirancang produk alat bantu pengangkat keranjang pembawa benda kerja dengan tenaga penggerak kombinasi penumatik dan hidrolik. Gambar rancangan alat bantu dapat dilihat pada Gambar 10.

Produk ini menggunakan tenaga penggerak utama berupa tekanan udara sebesar 6 bar (pneumatik) yang langsung dialirkan melalui pipa-pipa yang mengalirkan tekanan udara ke semua mesin di pabrik yang memerlukan tekanan udara dalam pengoperasiannya. Pipapipa ini mengalirkan tekanan udara sebesar maksimal 6 bar. Produk ini memanfaatkan mekanisme hidrolik untuk membuat tekanan 6 bar tersebut mampu mengangkat keranjang pembawa benda kerja yang sangat berat beserta alas pengangkatnya. Dengan demikian, tidak diperlukan biaya tambahan untuk mengalirkan tenaga pada produk ini. Produk ini juga menggunakan Programmable Logic Controller (PLC) sederhana sebagai sistem kendali dalam pengoperasiannya, sehingga operator sangat mudah untuk menaikan atau menurunkan alat bantu ini. 
Alat ini memiliki beberapa komponen utama, yaitu pipa aliran tekanan udara sebagai jalur mengalirnya tekanan udara untuk mengangkat atau menurunkan alat, solenoid valve sebagai aktuator buka tutup katup pada alat,

Programmable Logic Controller (PLC) sebagai sistem kendali dari alat, piston sebagai bagian alat yang menggunakan prinsip hidrolik untuk mengangkat atau menurunkan keranjang, pressure gauge untuk mengukur tekanan udara, pegas untuk menahan bagian bawah piston agar tidak menghantam pipa bagian bawah, pipa hidrolik yang berisi fluida untuk menjalankan mekanisme hidrolik dari alat, pipa kuras fluida untuk menguras dan mengganti fluida di dalam pipa hidrolik, dan lokator keranjang untuk menahan keranjang ketika sedang diangkat atau diturunkan.

Alas penahan keranjang yang terbuat dari baja karbon perlu mampu mengangkat beban dan berat alas hingga $317 \mathrm{~kg}$. Maka dari itu, alas tersebut diuji tekan dengan gaya terdistribusi sebesar $400 \mathrm{~kg}$ dengan menggunakan software Solidworks. Hasil pengujian pada Gambar 11 menunjukkan bahwa tidak ada titik kritis yang berpotensi menyebabkan lengkungan atau bahkan patahan pada alas ketika diberi beban.

PLC pada alat yang dirancang berfungsi untuk menjalankan perintah sesuai dengan pogram instruksi yang diberikan. Program yang diberikan mengikut ladder diagram yang dapat dilihat pada Gambar 12.

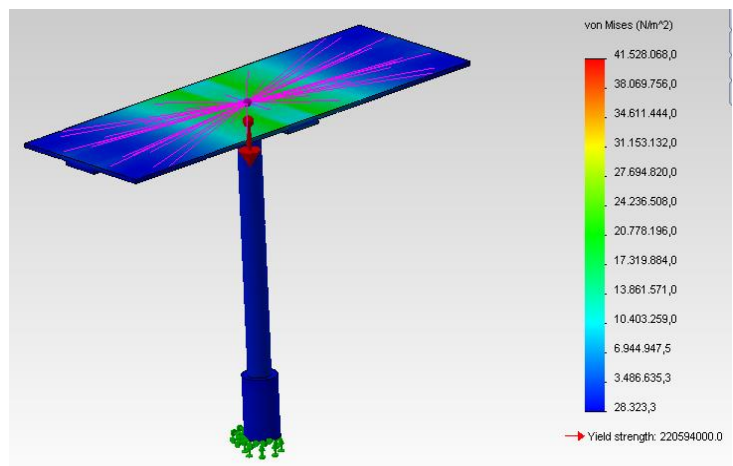

Gambar 11. Hasil Uji Tekan pada Alas Alat Bantu Pengangkat Keranjang Benda Kerja

Cara kerja untuk rancangan produk ini adalah saat operator menekan tombol untuk menaikkan keranjang yaitu $I 1, \quad I 1$ akan menyalakan dummy yaitu Q4 yang akan membuka jalur udara masuk yaitu Q1 sehingga udara bertekanan akan menekan-

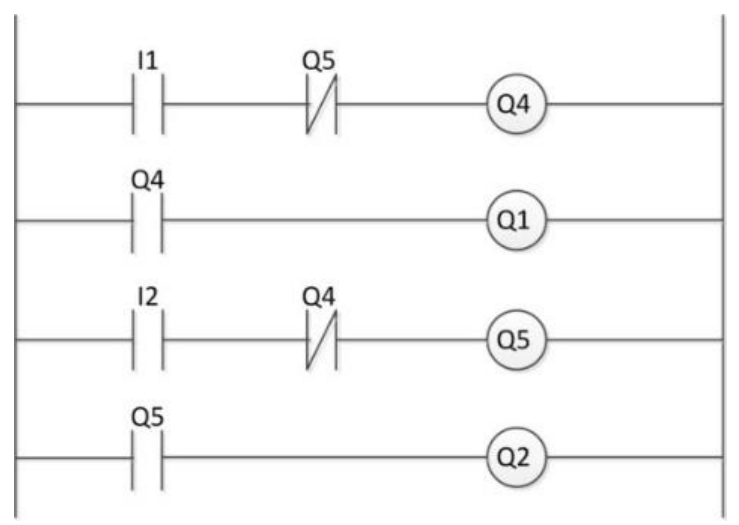

Gambar 12. Ladder Diagram

piston kecil hingga piston besar akan naik sesuai dengan ketinggian yang diinginkan oleh operator. Saat operator menekan tombol untuk menurunkan keranjang yaitu 12,12 akan menyalakan dummy yaitu Q5 yang akan menutup valve pada pipa masuk udara dan membuka valve pada pipa keluar udara untuk keluar sehingga rancangan produk akan turun sesuai yang diinginkan operator atau hingga keranjang menyentuh kembali lantai permukaan dan udara telah keluar semua. Jika I1 dan 12 tidak ditekan, maka posisi ketinggian alas pengangkat keranjang tidak akan bergerak kembali. Dengan mekanisme tersebut, pekerja dapat leluasa mengatur ketinggian keranjang yang diinginkan hanya dengan menekan tombol I1 dan 12 .

Untuk dapat mengangkat keranjang dengan berat yang dapat mencapai $250 \mathrm{~kg}$ beserta dengan alasnya seberat $47 \mathrm{~kg}$, tekanan angin harus dapat mendorong jumlah beban sebesar kurang lebih $317 \mathrm{~kg}$. Dengan luas permukaan piston kecil sebesar $28,29 \mathrm{~cm}^{2}$ dan luas permukaan piston besar sebesar $254,57 \mathrm{~cm}^{2}$,

maka tekanan minimal yang perlu diberikan kepada piston kecil untuk membuat keadaan setimbang pada sistem adalah sebesar 1,58 bar. Maka, tekanan udara yang dimiliki pabrik yaitu sebesar 6 bar sudah mampu mendorong piston kecil untuk membuat piston besar naik dan mengangkat keranjang.

Setelah mengembangkan alat yang dapat mempermudah operator, dilakukan analisis terhadap beban kerja pengangkatan operator setelah mengambil benda kerja pada keranjang bagian bawah dengan menggunakan alat bantu tersebut. Pengujian dilakukan ketika pengguna menaikan keranjang hingga Hasil perhitungan beban pengangkatan menggunakan metode $\mathrm{NIOSH}$ menunjukkan bahwa rata-rata $\mathrm{LI}$ operator 
OP10 sebesar 0,73 , operator OP20 sebesar 0,81 , dan operator QC sebesar 0,46. Nilai RULA posisi pengangkatan benda kerja dari keranjang bagian bawah maupun atas sebesar 4. Nilai NASA-TLX dari operator OP10 sebesar 61 , operator OP20 sebesar 64, dan operator QC sebesar 66. Dengan demikian, perbaikan sistem kerja dengan menambah alat pengangkat keranjang di stasiun kerja produksi crankcase di PT.X berhasil membuat beban kerja pekerjanya menjadi jauh lebih ringan.

\section{Kesimpulan}

Pada penelitian ini, masalah yang diselesaikan adalah mengenai beban kerja pekerja yang melebihi batas yang dianjurkan. Dalam berbagai industri, masalah yang serupa dapat diselesaikan dengan metode dan hasil perbaikan yang dapat berbeda-beda. Pada masalah dalam penelitian, pengembangan alat bantu material handling paling tepat, karena pemangku kepentingan tidak menghendaki adanya perubahan bentuk keranjang atau penambahan pekerja di PT.X. Untuk memastikan bahwa beban kerja pekerja memang besar, dilakukan evaluasi dengan metode NIOSH, RULA, dan NASA-TLX. Ketiga metode ini dipilih karena merupakan metode yang paling tepat digunakan dalam permasalahan yang ada. Dengan demikian, penelitian ini menggunakan ketiga metode sebagai alat ukur beban kerja yang dapat diandalkan. Produk yang dikembangkan adalah alat bantu karena PT.X berusaha meminimasi biaya perubahan yang mungkin dilakukan. Perancangan ulang keranjang akan membuat ratusan keranjang jenis lama harus disingkirkan. Sistem material handling terotomasi untuk menggantikan keranjang juga membutuhkan investasi yang sangat besar.

Alat pengangkat keranjang sebagai alat bantu material handling yang dihasilkan terbukti mampu mengurangi beban kerja operator produksi yang bersangkutan sehingga beban kerja pekerja setelah menggunakan alat bantu berada dalam kondisi normal. Alat dengan menggunakan tenaga angin dan memanfaatkan mekanisme hidrolik ini menjadi solusi yang cukup aman dan tidak terlalu mahal untuk dapat diterapkan oleh PT.X. Selain itu, operator juga sangat mudah untuk mengoperasikannya, hanya dengan menekan tombol naik atau tombol turun untuk mengatur ketinggiannya. Dengan demikian, operator dengan dimensi tubuh seperti apapun tetap dapat menggunakan produk ini dengan baik.

Penelitian lebih lanjut dalam bidang ini dapat dilakukan di bagian lain di PT.X atau dapat dilakukan di perusahaan lain dengan tetap berfokus kepada ergonomi yang baik di tempat kerja. Inti dari perbaikan sistem kerja yang dapat dilakukan di semua tempat adalah bagaimana membuat pekerjaan dapat disesuaikan dengan kenyamanan pekerja, bukan pekerja yang harus menyesuaikan dengan pekerjaannya.

\section{Daftar Pustaka}

Ansari, N.A. \& Sheikh, M.J. (2014). Evaluation of work Posture by RULA and REBA: A Case Study. IOSR Journal of Mechanical and Civil Engineering, Vol. 11(4), 18-23.

Bappenas (2017). Perkembangan Ekonomi Indonesia dan Dunia triwulan 2017. Jakarta: Kedeputian Bidang Ekonomi Kamantrian PPN/Bappenas.

DiDomenico, A. \& Nussbaum, M.A. (2011). Effects of different physical workload parameters on mental workload and performance. International Journal of Industrial Ergonomics, Vol. 41(3), 255-260.

Hart, S.G. \& Staveland, L.E. (1988). NASATLX (Task Load Index). California: NASA Ames Research Center.

Hart, S.G. (2006). Nasa-Task Load Index (NASA-TLX); 20 Years Later. Proceedings of the Human Factors and Ergonomics Society Annual Meeting 2006, Vol. 50, 904908.

Jonathan, G.K. (2016). Maintaining Health and Safety at Workplace: Employee and Employer's Role in Ensuring a Safe Working Environment, Journal of Education and Practice, Vol. 7(29), 1-7.

Knudson, D. (2007). Fundamentals of Biomechanics. Chico: Springer.

McAtamney, L. \& Corlett, E.N. (1993). RULA: a survey method for the investigation of workrelated upper limb disorders, Applied Ergonomics, Vol. 24(2), 91-99.

Middlesworth, M. (2007). A Step-by-Step Guide: Rapid Upper Limb Assessment (RULA). Ergonomics Plus, [Online], Diakses dari: http://ergo-plus.com/wpcontent/uploa ds/RULA-A-Step-by-StepGuide1.pdf [2018, 6 Februari). 
Phinyomark, A., Quaine, F., \& Laurillau, Y. (2014). The Relationship between Anthropometric Variables and Features of Electromyography Signal for HumanComputer Interface. Applications, Challenges, and Advancements in Electromyography Signal Processing, 321353.

Ulrich, K. T., \& Eppinger, S. D. (2012). Product Design and Development. New York: McGraw-Hill.

Stevenson, M. G. (1996). Principles of Ergonomics. Australia: Center for Safety Science-University of NSW.

Sutalaksana, I. Z., Anggawisastra, R., \& Tjakraatmadja, J. H. (2006). Teknik
Perancangan Sistem Kerja. Bandung: Departemen Teknik Industri ITB.

Trujillo, A.C. (2011). Evaluation of Electronic Formats of the NASA Task Load Index. Virginia: NASA Langley Research Center.

Umami, M. K., Hadi, A. D. R., \& Agustina, F. (2014). Evaluasi Ergonomi Aktivitas Manual Material handling pada Bagian Produksi di CV. GMS, Bangkalan. Jurnal Rekayasa Sistem Industri, Vol. 3(2), 65-70.

Waters, T. R., Putz-Anderson, V. \& Garg, A. (1994). Applications Manual For The Revised NIOSH Lifting Equation. Cincinnati Ohio: U.S Departement Of Health And Human Services. 
DOI: http://dx.doi.org/10.26593/jrsi.v7i2.2832.85-98

Halaman ini sengaja dikosongkan

This page is intentionally left blank 